\title{
US universities go East
}

\author{
The global expansion of Western universities is not without challenges but can provide manifold opportunities, \\ particularly in the Middle East.
}

T⿳⺈⿴囗十大: he ideal of the cosmopolitan, the citizen of the world, is not a modern one, and is particularly exemplified in science. John Sexton, former president of New York University (NYU), invoked this image in his essay "Global Network University Reflection” promoting NYU's plan to expand to the Middle East, stating, "A cosmopolitan maintains his or her sense of place, country, ethnicity, religion, and culture, even while embracing, respecting, learning from, and adapting to global diversity."

Sexton and leaders of other US universities believed that expanding the successful model of a liberal arts and science education into different cultures would be a means to further this vision. Potential host countries, such as wealthy Gulf nations like Qatar and the United Arab Emirates (UAE), in turn saw an opportunity to expand their higher education system, provide their citizens with more choices and develop reputations as globally minded modern Arab countries.

This global extension of Western institutions has taken different forms. The simplest are research partnerships such as that between the King Abdullah University of Science and Technology (KAUST) and the University of Texas at Austin, the University of California, Berkeley, and Stanford University, which provided assistance to KAUST in hiring faculty and developing curricula when it was founded in 2009. The most ambitious plans involve full branch campuses that have the same admission standards, curricula and degrees as the home campus. Examples include Qatar's Education City in Doha, with a cluster of satellite campuses from Virginia Commonwealth University, Weill Cornell Medical College, Texas A\&M University, Carnegie Mellon University, Georgetown University and Northwestern University. The courses offered range from design and art history to chemical engineering, journalism and medicine; some include postgraduate degrees.

International branch campuses of US institutions are increasing in number, and as of 2016 there were 78 around the world-about one-third of all branch campuses in existence, according to a joint analysis by the Observatory on Borderless Higher Education at Oxford
University and the Cross-Border Education research team from Penn State and the University of Albany. Their locations span the globe from European countries to China, Hong Kong, South America, Africa and the Middle East.

But these ventures, particularly in the Middle East, are not without challenges and critics. Concerns include finding and retaining qualified teachers and students who meet the admission criteria of the affiliated institution. NYU opened its satellite campus in downtown Abu Dhabi in 2010 with 148 students; it has steadily grown since then and moved to a bigger campus on Saadiyat Island. The university met the challenge of student recruitment by partnering with the Fulbright organization to encourage the best students of highranking schools around to world to apply. Initially the Emirati applicants were often not prepared for NYU's level of instruction, and the university instituted a gap year to help students build up language and academic skills.

Does the recruitment of talented faculty to satellite campuses reduce their availability to students at home? NYU reportedly experienced some growing pains from such 'brain drain'. As faculty invested in branch campuses, their time and energy were drawn away from their local teaching and supervisory activities. In particular, the biology department at NYU felt the strain, with several faculty members involved in campuses overseas.

Sexton's expansion plans were met with resistance among NYU's faculty that contributed to a no-confidence vote in 2013, a nonbinding resolution. But Sexton continued to be supported by NYU's board of trustees, and the global expansion continued. And by many measures, such as international attendance and female graduation rates, NYUAD is a success story. It today has students from over 110 countries who learn to interact across cultural and socioeconomic backgrounds. Around 15\% of the students are from the UAE, and the student body is not segregated by sex.

An international campus provides great opportunities to confront and overcome stereotypes on all sides. In particular, the Western view of women's roles in societies in Middle Eastern and Gulf nations can be distorted. Kristin Gunsalus, affiliated faculty at NYUAD, stresses that Emirati society respects and honors women, but in some ways that may differ from those in the west. Cultural complexities aside, the benefit of education for women is easy to agree on. For female students from traditional families, who often are more reluctant to send their daughters abroad, having local access to a highly regarded institution can provide opportunities they otherwise would not have had. The first Minister of Youth in the UAE, H.E. Shamma Al Mazrui, is a female graduate of NYUAD.

Some critics see the influx of money into Western institutions as one of the main driving forces for their expansion. At a time when investment in research in the United States seems to be stagnant, endowments are flat and tuition costs cannot be raised much higher, foreign money can be seen as a welcome addition. But depending on local subsidies can be risky, as illustrated by the potential end of the operations in Singapore of the Biomedical Sciences at Johns Hopkins University in 2006 and the University of Nevada, Las Vegas, in 2013. Although the negotiations ultimately resulted in the universities' continued presence, they did highlight the vulnerability inherent in dependence on local support. In another example, Qatar had to decrease its budget for Education City when the global oil market took a downturn and substantial funding was anticipated to host the FIFA World Cup in 2022. While this will not affect the existence of the current branch campuses, it will lead to a reduction of some of the services offered.

Many more hard questions arise as part of such expansions: how should campuses integrate different political views, religions and sexual orientations? How can teachers and students practice critical thinking and exercise free speech while adhering to local laws? What is the best way to value local culture and language when all instruction is in English? These questions are not necessarily unique to satellite campuses, and lessons learned abroad may well help at home. And how else to tackle them if not by engagement and exposure that attempts to break down misconceptions?

Published online: 2 July 2018 https://doi.org/10.1038/s41592-018-0060-9 